\title{
NEUROLEPTANALGESIA FOR INTRAOCULAR SURGERY
}

\author{
W. M. JONES, M.D., F.R.C.P.(C), W. SAMIS, M.D., \\ D'Arcy Macdonald, M.D., F.R.C.s. (c), and H. W. Boyes, M.D."
}

INTRAOCULAR SURGERY is usually performed using a combination of heavy sedation and local nerve blocks., ${ }^{1,2}$ Occasionally, hypotension and respiratory depression are severe enough to require active resuscitation with oxygen, analeptic drugs, and a vasopressor. Most of these patients are elderly and are not monitored during the operation. In a few centres, general anaesthesia is used. It carries several drawbacks: $(a)$ the risk of postoperative nausea and vomiting and restlessness, (b) exposure to potent systemic agents, $(c)$ increased intraocular pressure from possible coughing and bucking on the endotracheal tube, and $(d)$ possible greater risk of iris prolapse and vitreous extrusion.

The authors felt that a technique retaining the use of local anaesthesia but employing neuroleptanalgesia as an adjunct would provide optimum conditions. Monitoring of the patient was considered vital to the successful application of the method, Neuroleptanalgesia (NLA) and anaesthesia was originally submitted as an anaesthetic technique by Decastro and Mundeleer in $1959 .^{3}$ Since that time, thousands of patients have been sedated and anaesthetized by this method with moderate success. ${ }^{4,5} \mathrm{~A}$ particular advantage cited has been the excellent tolerance by poor risk, geriatric patients. ${ }^{B}$

In 1965, Tait and Tornetta reported the use of NLA for intraocular surgery.7 They studied 35 patients undergoing cataract extraction and iridencleisis. They gave droperidol $10 \mathrm{mg}$. one hour preoperatively and Innovar $3-6 \mathrm{ml}$. in the operating room. They noted good analgesia for local anaesthetic injections and satisfactory sedation.

In 1966, Wine reported the use of Innovar in 50 patients undergoing cataract extraction. ${ }^{8}$ He was not impressed with the analgesia for the retrobulbar nerve block injection. There was a fairly high incidence of hypotension and respiratory depression. There was only intermittent monitoring of the patients in this study.

In 1967, Cameron described the use of NLA in 19 patients undergoing cataract extraction. ${ }^{9}$ He gave $5 \mathrm{mg}$. of droperidol 90 minutes preoperatively. In the operating room, phenoperidine in dosages of $1.0-2.5 \mathrm{mg}$. was given intravenously. No retrobulbar blocks were performed. In seven patients an analeptic was necessary to restore respiratory function. In this high dosage range, fentanyl was too potent a respiratory depressant to be used without ventilatory assistance.

-Departments of Anaesthesia (Dr. Jones, Dr. Boyes) and Ophthalmology (Dr. Samis, Dr. Macdonald), Toronto Western Hospital and University of Toronto. Address requests for reprints to Dr. W. M. Jones, Department of Anaesthesia, Toronto Western Hospital, 399 Bathurst Street, Toronto $2 \mathrm{~B}$, Ontario.

Can. Anaes. Soc. J., vol. 15, no. 5, September 1968 


\section{Method and Materials}

The combination of a neuroleptic drug, droperidol, and an analgesic, fentanyl, produces the state of neuroleptanalgesia. For reasons to be cited later the constituent drugs droperidol and fentanyl were employed separately in this study instead of the commercially available Innovar (50:1 droperidol/fentanyl).

Droperidol is a butyrophenone derivative related to the original neuroleptic, haloperidol. It is a potent psychomotor sedative with the unique feature of producing a psychic detachment of the patient from his environment. Yet the patient is co-operative on demand. Droperidol has strong antiemetic effects as well as being a mild alpha-adrenergic blocker. It has a long duration of action of four to six hours, with some effects persisting up to 18 hours.

Fentanyl is a piperidine derivative, a cogener of pethidine. It has one thousand times the analgesic potency of pethidine on a weight basis. Its emetic effects and cardiorespiratory depressant properties do not share this same relationship, however. Fentanyl has a vagal-like action, producing a moderate bradycardia. It has a rapid onset of action with a short duration ( 30 minutes).

One hundred consecutive adult patients undergoing intraocular surgery were studied and observed. Their age and sex distribution is shown in Table I. The common concurrent medical problems associated with the patients are noted in Table II.

TABLE I

Age And Sex Distribution

\begin{tabular}{lcc}
\hline \hline & Number & $\%$ \\
\hline Male & 46 & 46 \\
Female & 54 & 54 \\
70 and up & 53 & 53 \\
$60-69$ & 26 & 26 \\
$50-59$ & 20 & 20 \\
Under 50 & 1 & 1 \\
\hline
\end{tabular}

TABLE II

\begin{tabular}{lr}
\hline Preoperative problems & $\%$ \\
\hline Hypertension (160/90) & 45 \\
Cardiac arrhythmias & 8 \\
Anaemia (less than 10 gm.) & 5 \\
Chronic chest disease & 22 \\
Glaucoma & 35 \\
\hline
\end{tabular}

Droperidol was given by the intramuscular route one hour preoperatively as premedication. The dose was based on the age of the patient, as follows: 70 and over, $5 \mathrm{mg}$.; $60-69,7.5 \mathrm{mg}$; under $60,10 \mathrm{mg}$. On arrival in the operating room, an infusion of 5 per cent glucose in water was started, to facilitate drug injections. A blood pressure cuff was placed on the arm, an $S$ and $W$ pulse meter on the thumb, and oxygen was insufflated over the patient's face at 10-15 L./min.

While the surgeons scrubbed, fentanyl $0.06 \mathrm{mg}$. (one ampoule of $2 \mathrm{ml}$. (0.05 
$\mathrm{mg} . / \mathrm{ml}$ ) diluted in $8 \mathrm{ml}$. normal saline) was given intravenously. Frail patients were given $0.03 \mathrm{mg}$. and robust patients $0.08 \mathrm{mg}$. No further droperidol or fentanyl was given.

The ophthalmologists performed the facial (Van Lint and O'Brien techniques) and retrobulbar nerve blocks using 10-15 ml. of 2 per cent lidocaine (Xylocaine ${ }^{\mathbb{P}}$ ) with hyaluronidase and epinephrine 1/100,000. In hypertensive patients (160/90), no epinephrine was used.

The patient was draped with particular care to place the eye drape clear of the face in order to provide free ventilation. The blood pressure, pulse rate, respiratory rate, and level of consciousness were monitored in each patient. Tidal and minute volumes of respiration were measured preoperatively and postoperatively in 25 patients. Arterial blood gas studies were performed in eight patients.

The sedative response on arrival in the operating room, the analgesic response to the local nerve block injections, and the level of sedation during the operation were assessed. Any complications associated with the study were noted.

After the operation was completed the patients were returned to their rooms. Those who had respiratory or circulatory complications were observed for a brief period in the recovery room.

\section{Results}

The degree of sedation on arrival in the operating room was graded as follows: excellent-drowsy, but rousable; moderate-eyes closed, but alert; minimal-eyes open, alert, talkative. The results were noted in Table III. Eighty per cent of the patients were adequately sedated. Two younger patients (under 40 ) were tense and required general anaesthesia for persistent restlessness and lack of co-operation.

TABLE III

Patient Response

\begin{tabular}{lccc}
\hline & $\begin{array}{c}\text { Sedation level } \\
\text { on arrival }\end{array}$ & $\begin{array}{c}\text { Analgesic response } \\
\text { to local injections }\end{array}$ & $\begin{array}{c}\text { Sedation level } \\
\text { during surgery }\end{array}$ \\
\hline Excellent & 35 & 52 & 67 \\
Moderate & 44 & 40 & 29 \\
Minimal & 21 & 8 & 5 \\
\hline
\end{tabular}

The analgesic response to the local injections were scored according to the following criteria: excellent-no visible reaction from the patient; moderate-facial grimace, squeezing of hands; minimal-body movement, turning head away from needle, vocal complaint. The results, as shown in Table III, were excellent in 50 per cent of the series.

The level of sedation during the operation was assessed as follows: excellentno voluntary movements, no talking, sleeping; moderate-some crossing of legs, occasional talking; minimal-talking, frequent movements. The results, as revealed in Table III, were excellent in 67 per cent of the patients. A further 29 per cent were moderately sedated. The improvement in sedation level was attributed to the more optimal time for droperidol to exert its effect. 
TABLE IV

Tidal and Minute Volumes (Mean)

\begin{tabular}{llr}
\hline \hline Preoperative & $450 \mathrm{ml}$. & $8 \mathrm{~L} . / \mathrm{min}$. \\
Postoperative & $350 \mathrm{ml}$. & $6.5 \mathrm{~L} . / \mathrm{min}$. \\
\hline
\end{tabular}

TABLE V

Arterial Blood Gas Studies

\begin{tabular}{|c|c|c|c|c|c|c|}
\hline \multirow[b]{2}{*}{ Patient } & \multicolumn{3}{|c|}{ Preoperative* } & \multicolumn{3}{|c|}{ Postoperativef } \\
\hline & $\mathrm{pH}$ & $\mathrm{PcO}_{2}$ & $\mathrm{P}_{\mathrm{O}_{2}}$ & $\mathrm{pH}$ & $\mathrm{PCO}_{2}$ & $\mathrm{Po}_{\mathrm{O}_{2}}$ \\
\hline $\begin{array}{l}1 \\
2 \\
3 \\
4 \\
5 \\
6 \\
7 \\
8\end{array}$ & $\begin{array}{l}7.40 \\
7.42 \\
7.38 \\
7.36 \\
7.38 \\
7.40 \\
7.37 \\
7.36\end{array}$ & $\begin{array}{l}42 \\
38 \\
42 \\
44 \\
42 \\
40 \\
42 \\
44\end{array}$ & $\begin{array}{l}92 \\
98 \\
86 \\
80 \\
82 \\
94 \\
88 \\
82\end{array}$ & $\begin{array}{l}7.38 \\
7.44 \\
7.36 \\
7.36 \\
7.36 \\
7.40 \\
7.34 \\
7.35\end{array}$ & $\begin{array}{l}45 \\
36 \\
44 \\
46 \\
46 \\
44 \\
46 \\
46\end{array}$ & $\begin{array}{l}84 \\
98 \\
80 \\
78 \\
76 \\
96 \\
80 \\
78\end{array}$ \\
\hline
\end{tabular}

Tidal and minute volumes were measured in 25 patients. Readings were taken with a Wright Respirometer ${ }^{\circledR}$ preoperatively and at the end of the operation. The results were shown in Table IV. The mean preoperative minute volume was $8 \mathrm{~L} . / \mathrm{min}$. The mean postoperative minute volume was $6.5 \mathrm{~L} . / \mathrm{min}$.

Arterial blood gas studies performed on eight patients revealed a tendency, as shown in Table V, to higher $\mathrm{Pco}_{2}$ and lower $\mathrm{Po}_{2}$ values after the narcotic (fentanyl) was given.

\section{Complications ANd Side-EFFects}

1. Bradycardia (less than $60 / \mathrm{min}$.) -15 per cent of the series. All these patients received atropine $0.4 \mathrm{mg}$. intravenously when bradycardia occurred.

2. Hypotension ( $25 \mathrm{~mm}$. $\mathrm{Hg}$ or more drop in systolic pressure) -5 per cent of the series. Two patients required vasopressor therapy (Aramine ${ }^{(8)} 1 \mathrm{mg}$. i.v.).

3. Tachycardia (100/min. or greater) -2 per cent of the study. This was due to epinephrine and it subsided spontaneously.

4. Respiratory depression-ten per cent of the series had a fall in respiratory rate to under 10/min. Eighty per cent of the 25 patients studied for minute volume changes showed a decreased level after fentanyl. Seventy-five per cent of the eight patients who had arterial blood gas studies had changes in the direction of depression.

5. Nausea and vomiting-one patient during the operation; three patients postoperatively. This was controlled with dimenhydrinate (Gravol ${ }^{\$}$ ) $50-100 \mathrm{mg}$. intramuscularly.

6. Extrapyramidal reactions -4 per cent of the series exhibited a mild tremor lasting 10-15 minutes. No treatment was required.

7. Chest wall rigidity-none. 
8. Psychotic behavioral changes-none.

9. Postoperative restlessness-none, although patients were observed by floor nurses to be generally more alert than when they were given heavy sedation with barbiturate, narcotic, and ataractic drugs. ${ }^{10}$

\section{Discussion}

Neuroleptanalgesia for intraocular surgery has been reported as a successful adjunct to local anaesthesia. ${ }^{7,9}$ In this present series of 100 patients, the largest reported to date, similar results were encountered. The patients were adequately sedated, relatively analgesic for the local anaesthetic nerve blocks, and remarkably free from side-effects. The ophthalmologist had a quiet, co-operative patient on whom to operate. He could devote his entire attention to the operation without wondering how his patient was doing under the drapes. The anaesthetist had satisfactory control of the drugs administered, with the knowledge that an antidote for any serious complication was readily available (atropine, analeptics, etc.).

In a previous study with sedation and local anaesthesia, the authors noted a consistent tachycardia and mild hypertension when epinephrine was used with the local anaesthetic drug. ${ }^{10}$ In this study, these signs were minimal, possibly due to the alpha-adrenergic blocking effect of droperidol.

For akinesia and a prolonged retrobulbar block, epinephrine should be used with the local anaesthetic agent. In hypertensive patients, the facial block was performed using lidocaine without epinephrine, while the retrobulbar block was done using lidocaine with epinephrine $1 / 100,000$ in minimal amount as only 2-3 ml. of local anaesthetic solution was required.

Droperidol has been reported to cause extrapyramidal reactions (torticollis, spasm of the facial muscles, swollen tongue, rigidity, and tremor). These are rare when the dose is $25 \mathrm{mg}$. or less. Four per cent of the patients in this series showed a mild tremor of the hands, which subsided spontaneously. In the event of such a reaction, the recommended treatment is atropine $0.4 \mathrm{mg}$. intravenously, followed by benztropine (Cogentin) $1 \mathrm{mg}$. intravenously or $2 \mathrm{mg}$. orally. Diphenhydramine (Benadryl ${ }^{\circledR}$ ) $50 \mathrm{mg}$. should be given intramuscularly for sustained antagonism. ${ }^{11}$

Fentanyl has a vagal stimulating action that is rarely a problem. Prophylactic atropine will reduce this effect to some extent. The authors preferred to give atropine intravenously if the pulse rate was less than 60 . This was required on 15 occasions.

Chest rigidity and decreased chest wall compliance were not seen in this series. It is a commoner accompaniment of neuroleptanaesthesia, where it is readily reversed by succinylcholine.,5

Respiratory depression was observed in many of the patients. The respiratory rate, tidal volume, and minute volume were reduced in many patients following the use of fentanyl. The limited arterial blood gas studies in this series revealed a tendency to respiratory acidosis and a decreased $\mathrm{Po}_{2}$. In no instance was the level of pathologic significance to the patient. Ferrari and Stephen reported 
depression of mean arterial $\mathrm{Po}_{2}$ from $84 \mathrm{~mm}$. $\mathrm{Hg}$ preoperatively to $73 \mathrm{~mm}$. $\mathrm{Hg}$ postoperatively in patients given neuroleptanaesthesia. ${ }^{12}$ In the current study, the patients were for the most part awake, and thus the blood gas depression was not as important.

To avoid the possibility of preoperative nausea and vomiting and respiratory depression, the authors preferred to use droperidol alone instead of Innovar as premedication. In the operating room, fentanyl was the drug of choice since its action was of short duration. The effects of droperidol last for hours and thus further injections of this drug should be avoided. This also minimizes the risk of extrapyramidal reactions. ${ }^{5}$

\section{SUMMARY}

Neuroleptanalgesia, using droperidol and fentanyl, as an adjunct to local anaesthesia, was assessed in 100 adult patients undergoing intraocular surgery. The method described offered the following advantages. (1) A satisfactory state of preoperative, operative, and postoperative sedation of the patient was obtained. (2) Local anaesthesia was performed in a relatively painless environment. (3) Monitoring of patient's vital signs to detect and treat any respiratory or circulatory depression was provided. (4) The patient and surgeon were reassured that an anaesthetist was looking after the patient. (5) The surgeon was able to devote his full attention to the operation. (6) Complications and morbidity were low.

\section{RÉSUMÉ}

La neuroleptanalgésie, utilisant le dropéridol et le fentanyl comme compléments à l'anesthésie locale, a été étudiée chez 100 malades adultes soumis à la chirurgie intra-oculaire. La technique décrite présentait les avantages suivants: (1) On a obtenu une sédation pré, per et post-opératoire satisfaisante. (2) L'anesthésie locale s'est faite de façon relativement indolore. (3) On était pourvu de tous les appareils à enregistrer les signes vitaux afin de diagnostiquer et de traiter toute dépression respiratoire ou circulatoire. (4) Le malade et le chirurgien étaient rassurés par la présence d'un anesthésiste qui surveillait l'opéré. (5) Le chirurgien pouvait accorder toute son attention à l'opération. (6) Les complications et les effets secondaires ont été rares.

\section{ACKNOWLEDGMENTS}

This study was supported by McNeil Laboratories (Canada), Don Mills, Ontario. The authors wish to thank Drs. T. J. Pashby, H. R. Hausler, K. MacDonald, H. R. Sniderman, L. Chisholm, and H. P. Brent for submitting their patients to this study. In addition, they appreciated the clinical support of Drs. C. P. Crompton, R. L. Weston, M. Krestow, and G. D. Dixon during the anaesthetic phase of the study. Finally, they wish to thank Mrs. M. J. Macklin, Nursein-charge of the ophthalmologic operating suite, for her co-operation, suggestions, and assistance. 


\section{REFERENCES}

1. Schlossman, A. Combined Anaesthesia in Intraocular Surgery: E.E.N.T. Monthly. 41: 396 (1962).

2. Ingram, H, V. \& Armstrong-Davidson, M. H. Intraocular Surgery with Local Analgesia and Heavy Sedation. Lancet. 1: 1321 (1961).

3. Decastro, J. \& Mundeleer, P. Anaesthesia sans barbiturique: la neuroleptanalgesia. Anesth. et analg. 16: 1022 (1959).

4. Nusson, E.: Experience with Neuroleptanalgesia. Anaesthetist. 11: 17 (1962).

5. Corssen, G.; Domino, E. F.; \& Sweet, R. B. Neuroleptanalgesia and Anaesthesia: Pharmacologic and Clinical Considerations. Anesth. \& Analg. 43: 744 (1964).

6. Aubry, U.; Dents, R.; KeÉri-Szánto, M.; \& Parent, M. Factors Affecting Survival of the Geriatric Patient after Major Surgery. Canad. Anaesth. Soc. J. 12: 510 (1965).

7. TaIt, E. C. \& TornetTA, F. J. Neuroleptanalgesia as Adjunct to Local Anaesthesia in Intraocular Surgery: A Preliminary Report. Am. J. Ophthal. 59: 412 (1965).

8. WINe, N. A. Sedation with Neuroleptanalgesia in Cataract Surgery. Am. J. Ophthal. 61: 456 (1966).

9. Cameron, F. M. Neuroleptanalgesia for Cataract Surgery. Correspondence, Brit. J. Anaesth. 39: 605 (1967).

10. Jones, W. M.; Samis, W.; Macdonald, D'Arcy; \& Boyes, H. W. Anaesthesia for Intraocular Surgery. Can. J. Ophth. In press.

11. Krantz, J. C. \& Carr, C. J. Pharmacologic Principles of Medical Practice. Baltimore: Williams and Wilkins (1965).

12. Ferratu, H. A. \& Stephen, C. R. Neuroleptanalgesia, Pharmacology and Clinical Experiences with Droperidol-Fentanyl. South. M. J. 59: 815 (1966). 